ISSN: 2162-3104 Print/ ISSN: 2166-3750 Online

Volume 8, Issue 4 (2018), pp. 1748-1763

(C) Journal of International Students

http://jistudents.org/

doi: $10.5281 /$ zenodo. 1468082

\title{
Exploring the Academic English Socialization of International Graduate Students in Taiwan
}

\author{
Shu-Wen Lan \\ National Pingtung University of Science \& Technology, Taiwan
}

\begin{abstract}
Through 24 semi-structured interviews with non-native English-speaking (NNES) international graduate students, this study explores their academic English socialization experiences in Taiwan guided by Lave and Wenger's (1991) community of practice framework and Lee and Rice's (2007) concept of neo-racism. Throughout a complicated academic English socialization process, newcomers became increasingly competent in communicating with the university community in English. However, this process was not unproblematic; challenges included differential welcome and treatment, a relative lack of interaction with Taiwanese peers or students outside their own ethnic groups, and negative perceptions of their accents and non-fluent English. Findings suggest a need to stimulate deeper reflection on international students' experiences in host communities, where they are increasingly the targets of nationality-based discrimination.
\end{abstract}

Keywords: academic English socialization, community of practice (CoP), neo-racism, NNES international graduate students

One of the many effects of globalization has been the rapid internationalization of higher education institutions in the Asia Pacific region, and Taiwan is no exception (Chen \& Lo, 2013; Huang, 2018; Lin, 2017). International students in Taiwanese graduate schools reached record levels in 2015, despite an overall decline of 9\% in graduate enrollment between 2014 and 2015 (Taiwan Ministry of Education [MOE], 2015). To accommodate the educational needs of a growing population of linguistically and culturally diverse graduate students, many Taiwanese universities have begun to offer several graduate degree courses either partially or entirely in English (Huang, 2012). Studies have investigated how Taiwanese students, teachers, and administrators perceive the design, implementation, and effectiveness of English-medium instruction (EMI) courses (Chen \& Lo, 2013; Huang, 2018), yet little research has focused on the learning experiences of international graduate students in EMI courses in Taiwan (Chou, 2014).

International graduate students in Taiwan, similar to those elsewhere, are faced with the challenge of socializing into unfamiliar academic campuses and learning how to interact with members of their academic discourse communities (Cowley \& Hyams-Ssekasi, 2018; Kobayashi, Zappa-Hollman, \& Duff, 2017; Li, Wang, Liu, Xu, \& Cui, 2018; Zappa-Hollman \& 
Duff, 2015). When this process occurs through the medium of English, it can be described as academic English socialization (AES). This task becomes even more difficult for non-native English-speaking (NNES) international graduate students who lack prior experience learning in English and often find it difficult to access the support and resources AES requires (e.g., Braine, 2002; Nambiar \& Ibrahim, 2013). Most prior research of NNES international graduate students' learning experiences has been conducted in English as a first language (L1) settings and framed by multiple obstacles such as a lack of confidence and fluency in using English (Braine, 2002), insufficient familiarity with English colloquialisms (Myles \& Cheng, 2003), and unawareness of host institutions' expectations (e.g., Lee \& Rice, 2007; Zappa-Hollman \& Duff, 2015). Only a few studies have examined NNES international graduate students' learning experiences in English as a foreign language (EFL) settings in the Asia Pacific region, specifically in South Korea (Lee et al., 2017) and Thailand (Lin \& Kingminghae, 2014).

According to Taiwan's Ministry of Education, in the 2014-2015 academic year, 4,439 NNES international graduate students ( $70 \%$ of all 6,305 international graduate students) were enrolled in Taiwanese higher education institutions (MOE, 2015). Given this growing presence, a better understanding of NNES international graduate students' AES experiences is urgently needed. Previous studies have tended to treat NNES international graduate students as a homogeneous group and thus overlooked the various tensions, challenges, and levels and types of discrimination faced by students of different nationalities (e.g., Chou, 2014; Chou, Roberts, \& Ching, 2012). With the aim of filling the aforementioned gaps, the present study compares the AES experiences of two groups of NNES international graduate students in Taiwan: from within and outside the Asia Pacific region, namely Vietnam and Burkina Faso. This work is guided by two theoretical frameworks, communities of practice (CoPs; Lave \& Wenger, 1991) and neo-racism (Lee \& Rice, 2007), each of which are described in detail in the next section.

\section{LITERATURE REVIEW}

\section{International Students' AES Experiences}

As an area of concern and a research topic, AES has grown dramatically in recent years (Duff, 2010). Relevant studies involving NNES international graduate students have been conducted in L1 English academic systems in the United States and Canada (e.g., Morita, 2004; Myles \& Cheng, 2003; Seloni, 2012). Morita's study, grounded in CoP theory, examined how six first-year master's students from Japan negotiated their participation and membership in their new English-speaking classroom communities in Canada and revealed their discomfort stemming from perceived differences between their current educational setting and their homes, communities, or prior school experiences. Myles and Cheng (2003) invited 12 NNES international graduate students to reflect on their academic and social experiences in a Canadian university. By exploring these students' beliefs, perceptions, and feelings, the researchers captured their processes of becoming legitimate members of new academic communities and corresponding impacts on their academic outcomes. Similarly, Seloni (2012) investigated AES experiences of six NNES first-year doctoral students in the United States, focusing on their reactions and adaptations to academic demands. Results illustrated how these students sought to become legitimate members of their academic communities and how their literacy practices influenced their socialization into academic writing environments.

Taken together, the findings of these three studies suggest that NNES international graduate students' academic performance, outcomes, and success manifestly involve the wide 
scope of AES experiences accompanying the cultivation of academic knowledge, social relationships with members of their academic communities, and disciplinary knowledge in an English-as-a-second-language context. These studies also concur that while it is necessary for NNES international graduate students with diverse languages, cultures, and educational backgrounds to become legitimate members of their new academic communities, this assimilation can only happen if these students develop close associations with the host academic culture through interaction with its members (e.g., course instructors, classmates, advisors, and peers). The same three studies, in line with increasing scholarly interest in the sociocultural aspects of second-language learning (see Lantolf, Thorne, \& Poehner, 2015), revealed that social interactions with members of the host university community are fundamental to NNES international graduate students' AES.

\section{Theoretical Frameworks for Conceptualizing Academic English Socialization}

\section{Theoretical Framework 1: Community of Practice}

To understand NNES international students' AES experiences, researchers have applied Lave and Wenger's (1991) concepts of CoP and legitimate peripheral participation (LPP; e.g., Belcher, 1994; de Oliveira \& Lan, 2012; Ha \& Kim, 2014; Morita, 2004; Seloni, 2012). In line with Vygotsky's (1978) sociocultural theory, which suggests that social interaction is a generative learning context and therefore centrally important to learning, Lave and Wenger (1991) proposed that learning is a process of growing participation in a CoP through interaction with more experienced community members/experts. Lave and Wenger proposed LPP to denote the learning process by which newcomers gradually became full participants in their chosen profession/CoP.

The present study's theoretical framework draws on CoP and LPP to define AES as a learning process by which NNES international graduate students move from peripheral to full participation in their university community. Throughout this process, it is crucial that, as newcomers, such students have access to knowledge resources and opportunities to interact closely with more experienced community members (de Oliveira \& Lan, 2012; Morita, 2004; Myles \& Cheng, 2003; Seloni, 2012), as such interactions are critical to students' development of academic English, and - by gradually taking on more complicated academic English taskstheir eventual ability to perform literacy activities expected of full community members.

\section{Theoretical Framework 2: Neo-Racism}

Despite its various advantages, the CoP/LPP framework favors positive outcomes, including smooth and harmonious learning processes for newcomers (e.g., Kerno Jr., 2008) and thus neither predicts nor explains the challenges, conflicts, and tensions that international students may encounter. Past research on such students' AES has revealed positive and negative outcomes and posited that a neo-racism framework can capture the conflict, tension, power issues, and discrimination these students are likely to encounter (Lee et al., 2017; Lee \& Opio, 2011; Lee \& Rice, 2007). At the risk of oversimplifying, neo-racism holds that overt racism is subsumed in certain settings, and its focus shifts to "otherness" (Balibar, 1991).

More recently, Lee and Rice (2007) applied neo-racism as a framework for investigating the experiences of 24 students from 15 foreign countries attending a U.S. university. Participants encountered difficulties including perceptions of unfairness, lack of hospitality, and cultural intolerance based on biological race as well as on foreign-national status, cultural attributes, and national origin. Guided by the same framework, Lee and Opio's (2011) 
interviews with 16 African student athletes from seven African countries studying in the U.S. revealed that Americans' negative assumptions, such as underestimation of athletes' desire to learn, undermined the African students' academic success. Many African student athletes reported that their academic advisors, due to underestimating the students' willingness to learn, encouraged them to take light course loads in presumably easier fields of study. However, these academic advisors might not have realized that some undergraduate degrees carry relatively little value in African countries. Lee and Opio (2011) further found that these African student athletes experienced negative stereotyping and discrimination solely based on their race and region of origin. Lee and Rice (2007) stressed that neo-racism "does not replace biological racism but rather masks it by encouraging exclusion based on the cultural attributes or national origin of the oppressed" (p. 389); that is, individuals no longer discriminate only based on race but instead on the idea that certain cultures are either unwilling or unable to assimilate into the mainstream or majority. Interestingly, however, using neo-racism as a lens to study international students' experiences has been largely limited to English-speaking Western contexts, despite the increasing internationalization of higher education in non-Western nations, notably Taiwan. The current study aims to address this gap.

\section{International Student Experiences in Asia}

Against the backdrop of globalization, the Asia Pacific region has seen a sharp rise in international students, prompting studies of their experiences (especially NNES students) that have tended to focus on students' adaptation to local academic and social life (e.g., Lin \& Kingminghae, 2014). In a Taiwanese context, recent research on the internationalization of higher education has often treated international students of different nationalities homogeneously (Chou, 2014; Chou et al., 2012; Jenkins \& Galloway, 2009; Lau \& Lin, 2014).

Although national differences within the 'international students' category have not been central to the above-mentioned research, some findings have suggested that such students' adjustment challenges may differ by nationality. For example, Lee, Jon, and Byun's (2017) application of a neo-racism framework to student experiences in South Korea revealed that Chinese students reported greater difficulties and more unfair treatment than their Englishspeaking counterparts from North America and Europe or even from more-developed countries in Asia, such as Japan. Similar results were derived from a case study conducted in South Africa (Lee, 2017).

Based on the above literature, the present study was guided by the following research questions:

1. How do different groups of NNES international graduate students describe their AES experiences?

2. What challenges do different groups of NNES international graduate students encounter in their AES experiences?

\section{RESEARCH METHOD}

\section{Research Context}

This study employed qualitative methods to investigate NNES international graduate students' AES at a university in southern Taiwan. In 2014, this institution hosted approximately 2,000 graduate students and 9,400 undergraduates, most of whom were studying science, 
engineering, or agriculture - all popular subjects with international students. Among the 173 international graduate students in 2014, approximately $80 \%(n=134)$ were from NNES countries (Department of International and Cross-strait Education, 2015). Of those, most hailed from Southeast Asia and Africa followed by South America and Europe.

\section{Participants}

Data were collected during the 2015-16 and 2016-17 academic years through multiple semi-structured interviews with eight of the university's NNES international graduate students (four women and four men, aged 23-34 [M=30]). Only degree-seeking international graduate students were selected for two reasons: (1) at the target university, most international students were enrolled in graduate rather than undergraduate programs; and (2) compared to exchange students who only remained in Taiwan for a brief period, degree-seeking international students stayed in the university environment long enough to reflect upon whether and how they were challenged and supported in their AES experiences. To reduce non-nationality-related variables among participants, selected students were all studying the hard sciences.

Multiple semi-structured interviews were conducted with each participant because this technique has been shown to foster stronger rapport between the researcher and participants; this allows participants to feel more comfortable describing difficult or emotionally charged experiences, thereby enhancing the overall quality of interview data (Merriam, 2009). Recruitment consisted of purposive sampling, in which the researcher sought information-rich cases that could provide insights into AES experiences in Taiwan with a focus on participantperceived challenges. The eight participants were invited in part because they had volunteered to attend an English Improvement Course for Foreign Students, implying that all students perceived their English proficiency to be low. The English Improvement Course was taught by a Taiwanese professor who had received her Ph.D. from a research university in the U.S. All international graduate students were required to obtain a score of at least 650 out of a possible 990 on the Test of English for International Communication (TOEIC). Students attending the English Improvement Course had pre-intermediate to intermediate English proficiency, with an average TOEIC score of 580. Four participants self-identified as being from Vietnam; the other four identified as being from Burkina Faso. At the start of the study, three Vietnamese and three Burkinabé participants were first-year master's students; the remaining two were firstyear Ph.D. students. None had arrived in Taiwan earlier than August 2015.

\section{Data Collection}

Each participant was interviewed three times for 1 to 2 hours per session. The first round of interviews was conducted near the beginning of the participants' first semester in Taiwan and sought to understand their demographic backgrounds, expectations about their studies, and initial perceptions of Taiwan and the university. The second round was conducted at the end of the first semester, aiming to understand participants' adjustment to the university's academic and social life, their interactions with members of the university community, and any specific English-language challenges the participants faced. The final round of interviews was held in the participants' third semester and explored how they had dealt with the above-mentioned English-language challenges, what resources they had needed to study in Taiwan, and if/how their perceptions had changed since their arrival. In the second and third interviews, all eight students were asked to describe their experiences while studying in Taiwan, focusing on instances in which they perceived unfairness, discrimination, or other challenges while 
becoming socialized into the university community. All interviews were conducted in English, audio-recorded, transcribed verbatim, and checked for accuracy.

\section{Data Analysis}

Analysis began after completing all interviews. Participants' descriptions of their AES experiences constituted the primary interview data of interest. Data were coded using open coding, and emerging themes were analyzed individually and across interviews with specific reference to CoP and LPP (Lave \& Wenger, 1991; Wenger, 1998) and neo-racism (Lee \& Rice, 2007; Lee et al., 2017). Initial codes were shifted and modified as the researcher reviewed and reconsidered the interview data using open coding and axial coding, following Glaser and Strauss' (1967) constant comparative analytic method.

After coding the interview transcripts, the researcher compared the codes and identified five key categories emerging from participants' descriptions of their AES experiences: (1) NNES international graduate students' adjustment to and social interaction with members of the university community; (2) resources and support offered by the university community; (3) English communication challenges; (4) accented-English and language-discrimination issues; and (5) social-interaction discrimination issues. By comparing codes and categories, convergent and divergent components of the data were revealed, forming the building blocks for NNES international graduate students' AES as defined by participants' experiences and perceptions.

\section{RESULTS}

The interview data revealed that participants from Vietnam and Burkina Faso interacted actively with members of their Taiwanese university community, particularly their co-nationals and advisors. They recalled that when they were newly arrived in Taiwan, these more experienced community members helped them face the initial English-language barrier and adapt quickly to their new academic and social environment. However, differences emerged between Vietnamese and Burkinabé participants' accounts of their AES perceptions and experiences, particularly in how they were welcomed and treated in the academic CoP.

\section{Integrating into English as a Medium of Instruction: Initial Barriers}

The first round of interview data revealed that none of the participants had received any exposure to EMI in their home countries. All participants described themselves as unprepared for EMI in Taiwan and recounted their difficulties in using English to communicate with course instructors and classmates and to participate meaningfully in class activities. Most participants experienced English communication breakdowns, particularly in EMI classroom settings. Participants 3 and 4 (P3 and P4) shared the following:

Being away from home, I meet many difficulties when I come [to Taiwan]. The first thing is English language difference. Sometimes I talk in class. The teacher, classmates, and especially the foreigners cannot understand my English. And when they talk, sometimes I cannot understand their English. I am very stressful when I attend classes here. -P3 (Vietnam)

When I came here, I confused when using English with the teachers and peers. Their accents are difficult to understand. It's difficult to understand the courses taught by the older Taiwanese professors. I also have problems in speaking English. I can't speak English easily. Most of the time in my hometown we speak 
French in class. So we use French words or French-English words to explain our ideas in class. So sometimes I don't know which kind of English words I should use to explain myself clearly in class here. - $\mathrm{P} 4$ (Burkina Faso)

Similar to P3 and P4, most participants reported that communication breakdowns in EMI classrooms resulted from (1) the foreignness of NNES international graduate students' own accents, and (2) the foreign accents of others, such as older Taiwanese lecturers and other international students. These findings echo Park, Klieve, Tsurtani, and Harte's (2017) discovery that international students in EMI courses faced difficulties because of their inability to understand English and because of other class members' and lecturers' diverse accents.

In addition to contributing to communication breakdowns, some participants' accented English was negatively evaluated by their Taiwanese instructors and classmates who preferred native-like English and required the NNES students to explain themselves repeatedly. For example, P2 (Vietnam, first-year Ph.D.) used English to communicate with foreign customers for 2 years in her workplace in Vietnam and thus was initially unconcerned about her English accent or about making mistakes. However, many Taiwanese lecturers and classmates in her EMI courses complained they could not understand her strongly foreign-accented English. P2 expressed frustration that these Taiwanese members of the university community negatively evaluated others' accented English based on the Taiwanese preference for standard American English. In her second interview, she vividly described how her attitude toward English had changed as a result:

\section{I thought I could use English for communication. But after I came to Taiwan, my instructors and classmates said that I have an English language problem because I was so heavy with an accent when I speak English. Every time when I speak, they cannot understand what I say. And I have to talk to them two or three times and discuss in another way. So I don't want to talk anymore and just listen in class.}

P2's statement suggests that she originally had what Jenkins, Cogo, and Dewey (2011) categorized as an English as a lingua franca (ELF) attitude. Her expectations of what constituted communication in ELF entailed mutual understanding with no regard for 'standardness' or 'correctness' based on native norms. P2 was willing to speak in her EMI courses when she was newly arrived in Taiwan, however, after pressure from local Taiwanese instructors and students, she gradually adopted their evaluative stance and learned more nativelike English (i.e., American English) to make herself understood in class. Along with increased self-monitoring of her English usage, she chose to speak less. Similarly, in a study of graduate students' class participation in EMI courses in Taiwan, Lin (2017) found that Taiwanese students tended to evaluate their own and their foreign classmates' use of English based on 'correctness' (i.e., standard American English) and that over time, international graduate students assimilated to their Taiwanese instructors' and classmates' attitudes toward English and increasingly engaged in self-monitoring of their EMI classroom communication.

\section{University-Provided Support}

When asked how they dealt with the initial language barrier in EMI courses, all participants highlighted the support from co-nationals who had been in Taiwan longer; in particular, this support took the form of knowledge- and resource-sharing in addition to English-language practice. In keeping with CoP and LPP theory, these experienced members willingly prepared those on the periphery for active and meaningful community membership (de Oliveira \& Lan, 
2012). P1 and P5 each noted that their co-nationals reached out when the students initially arrived in Taiwan. P1 explained,

My countrymate has been here for 4 years. Her English is better than me. So when she talks, she will teach me some words that I don't know. It is like she will speak some sentences and I will understand them. I feel positive when I talk with her in English. The way we talk English is the same. And I will understand what she said and she understands what I said. There is no language barrier. She helps me build my confidence in English more than before. -P1 (Vietnam)

In addition to regular English-language practice and improved confidence in spoken English, all participants mentioned that their primary bond with their co-nationals provided strong social and emotional support. P8 reported,

The first time we came to Taiwan, we didn't know anything about the campus and Taiwan. Some of our co-nationals helped us go many places and also we had trips. Our Chinese is not good. Outside the school, many people don't speak English. So our co-nationals gave us a lot of information and helped us buy things and go different places.

Beyond the initial settlement period, P6 described how his co-national peers encouraged him to continue his studies in Taiwan and not to give up, which he had considered due to his frustrations over the EMI-course language barrier:

My co-national said, "Don't worry! Some people have more English communication problems than you. They still can survive." So I know I am not the only one who has English problems.

Most participants emphasized that Taiwanese advisors also offered English-language learning resources and emotional support that helped them adjust to academic and social life in Taiwan. For example, P2 recounted how her advisor understood her desire to improve her accented English and suggested that she attend a special course to fulfill this need:

My advisor invited me to attend Advanced English Communication Course for Scientists. Through online learning, we study with one professor from America in class. The class has seven students from our university, including me, my country mate, and five local Taiwanese students. I think this English class is very good. It's important to find a native-speaker for English practice. The professor from America and my advisor helped me improve my English pronunciation and accent.

P7 also described his strong relationship with his advisor:

My advisor is like my father because he listens carefully to us. We can talk together and share feelings with him. He takes care of me. For example, if I have any problem I can call he anytime and he can give me some advices.

Previous research (e.g., de Oliveira \& Lan, 2012; Geeraert, Demoulin, \& Demes, 2014) has indicated that two major factors in international students' social adjustment and quality of English-language learning are reassurance and a sense of being understood. Similarly, the current study's participants were drawn into their CoPs by more experienced members who provided additional resources and practice for English-language learning along with strong social and emotional support, helping participants improve their accented English and increase 
their spoken English abilities. Thus, the trusting relationship participants developed with their co-national peers and advisors, who the participants considered to be experienced community members, supported the participants in becoming legitimate members of their new Taiwanese academic communities.

\section{Negative Encounters}

Despite the university community's support for the participants, their AES was not without challenges. Obstacles included differential treatment, especially how these students were made to feel welcome; lack of peer interaction with Taiwanese students and others from outside their own ethnicity; and among the African participants, negative perceptions of and remarks about their accented and non-fluent English, which appeared to be based on their nationality.

\section{Differential Treatment}

All Burkinabé participants reported being victims of considerable discrimination, whereas the Vietnamese did not report any such experiences; rather, Vietnamese participants stated they felt welcomed within the university community and experienced only minor difficulties in adjusting to social life in Taiwan.

I think people in Taiwan are friendly. They help me with many things because I don't know anything about Taiwan. When I just came here, they are very friendly and have kind heart to offer help. - P1 (Vietnam)

I feel Taiwanese students are a little bit shy when they see foreigners. They are shy to speak English. But they are friendly and nice to help. - P4 (Vietnam)

By contrast, Burkinabé participants reported experiencing rude behaviors that evoked discomfort, a sense of being unwelcome, and even anger:

[S]ometimes Taiwanese students, they are not civilized [sic]. They look at me and say, "See, look at the black guy." Everyone looked at me at the same time. I feel very bad. And they like to hide themselves and take my picture secretly. They don't ask for permission. But they just stand there and take a picture without communication. -P8 (Burkina Faso)

I remembered one time when I just came here. I went to 7-11 at our university to buy something. When I was walking around, I saw two students. When they saw me, they quickly put the wallet into the bag and grasped the bag. That day I was really angry. Maybe it was about my black color. Maybe they question me as a thief. I don't know. I was feeling I was not welcome here. -P5 (Burkina Faso)

The negative feelings aroused by such acts were occasionally exacerbated by on-campus social interactions with Taiwanese students. Three Burkinabé participants said they felt inferior and misunderstood based on negative media portrayals of Africa (e.g., as a place characterized by drugs and disease, particularly AIDS), which they felt made Taiwanese students reluctant to interact with them. The African participants also pointed out that local students' coldness compared unfavorably to the local townspeople's relatively friendly attitudes. P6 provided a rich description of these disparate attitudes:

Many Taiwanese students even think Africa is one country. Africa has almost 60 countries! In the TV, they always show you the images of drugs, diseases, AIDS. 
Africa is not like that! Many Taiwanese students may not have any idea about us. Even sometimes we went to Pingtung. It is very interesting that the people in town they are very kind. Different from the students on campus. Sometimes Taiwanese students don't want to speak English, and our Chinese is not good so the conversation is short.

Moreover, even when Burkinabé and Taiwanese students did interact, the Taiwanese seemed unwilling to use English and appeared uninterested in Burkina Faso and its culture, limiting their exchanges to a few superficial questions such as their interlocutors' names and ages.

I don't have the real relationship with Taiwanese people. Taiwanese students always stay close to their own group. They don't go to talk with others. If you want to talk with them, it is like they don't have any interest. They have another idea because I am black, because I come from other country. They have other minds about me. In that way, it is very hard to have a relationship with Taiwan people. -P7 (Burkina Faso)

All Burkinabé participants ascribed these problems to Taiwanese students' lack of interest in or knowledge of global issues, an analysis that coincides with some researchers' concerns (Huang, 2008; Lan \& Chang, 2016). In increasing numbers, university professors in Taiwan have also expressed concern over local students' lack of engagement with other areas of the world, blamed in part on the scarce coverage of international events on Taiwan's televised news programs.

\section{Language and Accented-English Discrimination}

Vietnamese participants contrasted the international graduate student community's diversity in English accents and pronunciations to what they perceived as the 'better' English pronunciation and intelligibility of local Taiwanese students. Vietnamese participants also took an especially negative view of Burkinabé graduate students' strong foreign accents and lower English proficiency. P1, for example, expressed positive perceptions of Taiwanese students' spoken English and English-pronunciation discrimination against students from Burkina Faso and Swaziland:

In my department, we have many Swaziland students and Burkina Faso students. They have the same pronunciation problem. I think their pronunciation is influenced by French and Siswati so sometime they speaking [English] is very difficult to understand. As for the students from Indonesia and Thailand, I think their pronunciation is similar with the Vietnam because we are Asian people. So we don't have big difference in Thailand, Vietnam, and Malaysia.

Another Vietnamese participant, P3, revealed her negative attitude toward Burkinabé graduate students' strong foreign accents and inferior English proficiency along with her dislike of these students' body odor. Additionally, she mentioned the traditional notion that Asian women should not go out with black people:

The African students are not good in English, even [if] their official language is English, their English is still not good. They like to speak a lot so [they] make you feel their English is good, but they are not native speakers. ... Maybe it's the 
culture. I don't really like to speak with African students. Their attitude is good, but I am Asian girl. ... If we go out with them, I feel that I don't like the males because sometimes they have smell.

As remarkable as P3's comments were, the neo-racism framework helps to clarify the nature of her thinking. P3's assumption that African students "are not good in English, even [if] their official language is English" echoed P6's (Burkinabé) observation among Taiwanese students: all Africans were lumped together as if Africa were a single country. P3 further revealed her ignorance by asserting that the Africans' official language was English despite Burkina Faso's official language actually being French.

Negative remarks about and perceptions of Burkinabé students based on their nationality and/or culture exemplify neo-racism and were shared by Taiwanese and Vietnamese students. These attitudes contrasted strongly with Vietnamese participants' positive perceptions of the English spoken by Taiwanese students and by other students from Asia (e.g., Thailand and Malaysia). Based on research conducted in the U.S., Lee (2007) concluded that neo-racism manifested as "negative stereotypes and inaccurate portrayals of one's culture; [and] negative comments about foreign accents" (p. 28), quite similar to those expressed by Vietnamese graduate students in the present study.

\section{DISCUSSION}

Three key themes emerged from participants' descriptions of AES experiences: the initial English-language barrier and their unpreparedness for EMI courses; the university community's support; and negative encounters based on their nationality. These themes are examined collectively herein to provide a more systematic discussion related to this study's research questions.

\section{RQ1: How do different groups of NNES international graduate students describe their AES experiences?}

Viewed through the lens of Lave and Wenger's (1991) concepts of CoP and LPP, participants' AES was a learning process during which they encountered an initial Englishlanguage barrier due to their diverse linguistic, cultural, and educational backgrounds while seeking to adapt to and become legitimate members of new academic communities. Along with their lack of exposure to EMI in their own countries, Vietnamese and Burkinabé participants both recalled that upon arriving in Taiwan, they experienced discomfort stemming from their self-perceived unpreparedness for EMI courses and from English communication breakdowns resulting from their accents. Such difficulties rendered it challenging to communicate with instructors and classmates and to participate meaningfully in EMI class activities. These findings echo those of prior studies on implementing EMI courses in Taiwan, namely that international students' English proficiency, ability to learn course content, and motivation remain questionable, as does the depth of class interaction and knowledge dissemination (Chou, 2014; Huang, 2012, 2018; Lau \& Lin, 2017; Lin, 2017).

Participants from Vietnam and Burkina Faso also highlighted the crucial roles of conational peers and advisors in offering knowledge, resources, and strong emotional support that helped students overcome their initial English-language barrier and gradually adapt to the new academic and social environment of the host university. Previous studies have found that access to knowledge resources and interaction with more experienced community members can assist 
NNES international students in developing their academic English and gradually taking on more complicated academic-English literacy tasks (Belcher, 1994; de Oliveira \& Lan, 2012; Kobayashi et al., 2017; Seloni, 2012). Nevertheless, findings from the current study indicate that participants' journeys to full community participation were fraught with conflict, tension, and power issues around negotiation and transformation based on their different nationalities.

\section{RQ2: What challenges do different groups of NNES international graduate students encounter in their AES experiences?}

This study's findings highlight country-of-origin-based variations in the tensions, challenges, and discrimination faced by international students in the Asia Pacific region. Unlike previous research that treated international students of many nationalities as a homogeneous group (Chou et al., 2012; Jenkin \& Galloway, 2009), recent studies rooted in neo-racism theory have compared international students' experiences based on their different nationalities (Lee, 2017; Lee et al., 2017). Similarly, the present study's comparison of the experiences of NNES international graduate students from Vietnam and Burkina Faso revealed that these two groups experienced differential treatment: the Burkinabé suffered from a lack of peer interaction with domestic students or students outside their ethnicity and were negatively affected by insensitive comments about their accented and/or non-fluent English. In contrast to the Vietnamese who felt welcomed and comfortable, the Burkinabé felt unwelcome, uncomfortable, and even angry, describing major difficulties in interacting with Taiwanese students. The Burkinabé tended to withdraw and avoid interacting with the Taiwanese given the perceived pervasiveness of Taiwanese students' negative perceptions of Burkina Faso and these students' skin color.

The neo-racism framework helps to identify the direct and indirect means by which NNES international students' capacity to become full members of their Taiwanese university community was undermined. Specifically, the neo-racism approach clarifies that not all NNES international graduate students faced the same hardships, with students from Vietnam expressing high levels of appreciation for Taiwanese students' welcoming attitudes and reporting little to no discrimination. In stark contrast, the Burkinabé encountered far greater challenges, including more negative remarks and discrimination and less peer interaction with Taiwanese students. These examples of neo-racism parallel those from previous studies that drew upon neo-racism to theorize international students' struggles (Lee, 2017; Lee et al., 2017; Lee \& Opio, 2011; Lee \& Rice, 2007).

Lee and Rice (2007) uncovered similar types of discrimination and misconceptions about international students, their cultures, and their home countries and argued that "international students are also often subject to misperceptions about their culture and so to easy stereotyping" (p. 399). As highlighted by one Burkinabé student, many Taiwanese students believed Africa to be a single country, implying they possessed no specific knowledge about Burkina Faso's history, culture, or even location. Unfortunately, by succumbing to their preexisting conceptions about students from Burkina Faso, the Taiwanese students and other international students compromised opportunities to enrich their knowledge of another culture. Many Taiwanese students will never travel to Africa, let alone Burkina Faso. However, students who had come to Taiwan from Burkina Faso brought a piece of that country and its culture with them to the Taiwanese university - an institution that supposedly exists to nurture inquiry and exploration of the unknown.

Echoing the local Taiwanese students' ignorance and apathy toward African countries and culture, Vietnamese students in the present study judged their classmates from Burkina Faso for talking excessively to impress people with the quality of their English. The Vietnamese also 
negatively contrasted what they perceived as the unintelligible accent of Burkinabé students with the well-pronounced, proficient English of those from Taiwan. As one Vietnamese student (P3) commented, "Maybe it's the culture. I don't really like to speak with African students. Their attitude is good, but I am Asian girl." Here, the student has revealed her truth: they are from Burkina Faso, but "I am Asian"; the students are not from the same country, nor are they from the same culture. Worse, P3 attempted to exonerate herself for her neo-racist attitude-or perhaps justify it - by contending that African students have an unpleasant body odor. As Lee and Rice (2007) explained,
$[D]$ iscrimination becomes . . . justified by cultural difference or national origin rather than by physical characteristics alone. . . . Neo-racism does not replace biological racism but rather masks it by encouraging exclusion based on the cultural attributes or national origin of the oppressed. (p. 389)

One might reasonably question whether participants from Burkina Faso were oppressed, but the evidence of their being denied entry into the CoP by their fellow students seems unequivocal in this regard. As noted previously, to successfully negotiate the university experience, all students must join the academic CoP facilitated by more experienced community members. If existing members are welcoming, then novice members are likely to become acculturated quickly. However, if new members are not welcomed, mentored, or considered valuable participants, they may never reach the level of participation that would most benefit them and the CoP as a whole.

\section{CONCLUSION}

Given that international students are universally encouraged to enroll in Taiwanese universities, the present study's findings suggest that more remains to be done to address the differential welcomes such students receive upon arrival. While the data revealed many instances of the university community functioning as it should - especially when the parties involved were the new students' co-national peers and advisors-results also suggest that Taiwanese universities should encourage engagement and interaction between local Taiwanese students and international students and perhaps especially NNES international graduate students. Instead of simply assuming that NNES international graduate students can and will socialize readily into the academic and social lives of Taiwanese universities, administrators and others should realize that such students encounter various barriers to smooth socialization, including negative attitudes and behaviors based on their nationalities, accents, cultures, and lack of EMI experience. Taiwan should develop new educational practices that encourage NNES international graduate students and host nationals (especially domestic students) to meaningfully engage with each other as equals in a spirit of mutuality both within and outside the EMI classroom. Doing so will help to increase international students' satisfaction and, ultimately, develop positive relations with potential future students and others in their home countries.

\section{IMPLICATIONS}

Currently, universities in Taiwan offer orientation programs for newly arrived international students in addition to pre-arrival information websites and magazines. However, along with the warm welcome and kind help from university administrators, faculty, and staff in assisting 
international students to adapt to a new landscape, the present study reveals the specific challenges NNES international graduate students encounter in communication with local Taiwanese students during their AES process. Challenges included differential welcome and treatment, a relative lack of interaction with Taiwanese peers or students outside their own ethnic groups, and negative perceptions of their accents and non-fluent English.

This study suggests a need to elicit deeper reflection on international students' experiences in host communities, where they are increasingly the targets of nationality-based discrimination. Additionally, more research is needed to identify new ways of fostering meaningful interactions between local and international students in Taiwanese universities. By encouraging local and international students to engage in ongoing interactions and communication, international graduate students can encourage local Taiwanese students to learn about other cultures and to develop cross-cultural awareness. In other words, Taiwanese university campuses with international graduate students provide local students a global context in which English is used as the medium of communication between peoples of different languages. Taking this a step further, international graduate students can assist local Taiwanese students in further developing their English communication skills.

\section{ACKNOWLEDGMENT}

The author appreciates the constructive and insightful comments from the reviewers. This work was supported by the Ministry of Science and Technology in Taiwan [grant no. MOST $105-$ 2410-H-020-012].

\section{REFERENCES}

Balibar, E. (1991). Es gibt keinen Staat in Europa: Racism and politics in Europe today. New Left Review, 186, 5-19.

Belcher, D. (1994). The apprenticeship approach to advanced academic literacy: Graduate students and their mentors. English for Specific Purposes, 13(1), 23-34. https://doi.org/10.1016/08894906(94)90022-1

Braine, G. (2002). Academic literacy and the nonnative speaker graduate student. Journal of English for Academic Purposes, 1(1), 59-68. https://doi.org/10.1016/S1475-1585(02)00006-1

Chen, D., \& Lo, W. (2013). Internationalization or commodification? A case study of internationalization practices in Taiwan's higher education. Asia Pacific Education Review, 14(1), 33-41.

Chou, C. H. (2014). International students' learning experiences in Taiwanese higher education (Unpublished doctoral dissertation). California State University, Fullerton.

Chou, C. P., Roberts, A., \& Ching, G. S. (2012). A study on the international students' perception and norms in Taiwan. International Journal of Research Studies in Education, 1(2), 71-84. doi:10.5861/ijrse.2012.v1i2.76

Cowley, P., \& Hyams-Ssekasi, D. (2018). Motivation, induction, and challenge: Examining the initial phase of international students' educational sojourn. Journal of International Students, 8(1), 109-130. doi:10.5281/zenodo.1101039

de Oliveira, L. C., \& Lan, S. W. (2012). Preparing nonnative English-speaking (NNES) graduate students for teaching in higher education: A mentoring case study. Journal on Excellence in College Teaching, 23(3), 59-76.

Department of International and Cross-strait Education. (2015). Statistics of International Graduates from 2009 to 2014. Retrieved September 15, 2015, from https://ois.moe.gov.tw/fs/html/Statistics.html 
Duff, P. A. (2010). Language socialization into academic discourse communities. Annual Review of Applied Linguistics, 30, 169-192. https://doi.org/10.1017/S0267190510000048

Geeraert, N., Demoulin, S., \& Demes, K. A. (2014). Choose your (international) contacts wisely: A multilevel analysis on the impact of intergroup contact while living abroad. International Journal of Intercultural Relations, 38, 86-96. https://doi.org/10.1016/j.ijintrel.2013.08.001

Glaser, B., \& Strauss, A. (1967). The discovery of grounded theory: Strangers for qualitative research. Chicago: Aldine Publishing Co.

Ha, M-J., \& Kim, H-C. (2014). E-learning education for academic literacy in computer-mediated communication. International Journal of Software Engineering and Its Applications, 8(1), 107118. http://dx.doi.org/10.14257/ijseia.2014.8.1.10

Huang, W. J. (2008). Global perspectives: Making connections between global education and Taiwan's EFL classrooms. Hwa Kang Journal of English Language \& Literature, 14, 1-18.

Huang, Y. P. (2012). Design and implementation of English-medium courses in higher education in Taiwan: A qualitative case study. English Teaching and Learning, 36(1), 1-51. doi:10.6330/ETL.2012.36.1.01

Huang, Y. P. (2018). Resistance to English-medium instruction practices: A qualitative case study. Teaching in Higher Education, 23(4), 435-449. doi:10.1080/13562517.2017.1421629

Jenkins, J., Cogo, A., \& Dewey, M. (2011). Review of developments in research into English as a lingua franca. Language Teaching, 44(3), 281-315. https://doi.org/10.1017/S0261444811000115

Jenkins, J., \& Galloway, F. (2009). The adjustment problems faced by international and overseas Chinese students studying in Taiwan universities: A comparison of student and faculty/staff perceptions. Asia Pacific Education Review, 10(2), 159-168.

Kerno Jr, S. J. (2008). Limitations of communities of practice: A consideration of unresolved issues and difficulties in the approach. Journal of Leadership \& Organizational Studies, 15(1), 69-78. https://doi.org/10.1177/1548051808317998

Kobayashi, M., Zappa-Hollman, S., \& Duff, P. (2017). Academic discourse socialization. In P. Duff \& S. May (Eds.), Language socialization - Encyclopedia of language and education (3rd ed.). New York: Springer.

Lan, S. W., \& Chang, M. M. (2016). Intertextuality-aware instruction of English newspapers in a college-based EAP reading class. Taiwan International ESP Journal, 8(2), 30-65. doi:10.6706/TIESPJ.2016.8.2.2

Lantolf, J. P., Thorne, S. L., \& Poehner, M. E. (2015). Sociocultural theory and second language development. In B. van Patten \& J. Williams (Eds.), Theories in second language acquisition: An introduction (pp. 207-226). New York: Routledge.

Lau, K., \& Lin, C. Y. (2014). The role of English as a lingua franca in social integration: The case of the international students of a university in Taiwan. The Asian Journal of Applied Linguistics, 1(1), $36-49$.

Lave, J., \& Wenger, E. (1991). Situated learning: Legitimate peripheral participation. Cambridge, UK: Cambridge University Press.

Lee, J. J. (2007). Bottom line-Neo-racism toward international students. About Campus, 11(6), 28-30.

Lee, J. J. (2017). Neo-nationalism in higher education: case of South Africa. Studies in Higher Education, 42(5), 869-886. https://doi.org/10.1080/03075079.2017.1293875

Lee, J. J., Jon, J. E., \& Byun, K. (2017). Neo-racism and neo-nationalism within East Asia: The experiences of international students in South Korea. Journal of Studies in International Education, 21(2), 136-155. https://doi.org/10.1177/1028315316669903

Lee, J. J., \& Opio, T. (2011). Coming to America: Challenges and difficulties faced by African student athletes. Sport, Education and Society, 16(5), 629-644. https://doi.org/10.1080/ 13573322.2011 .601144

Lee, J. J., \& Rice, C. (2007). Welcome to America? International student perceptions of discrimination. Higher Education, 53(3), 381-409. 
Li, J., Wang, Y., Liu, X., Xu, Y., \& Cui, T. (2018). Academic adaptation among international students from East Asian countries: A consensual qualitative research. Journal of International Students, 8(1), 194-214.

Lin, S. (2017). To speak or not to speak in the new Taiwanese university: class participation and identity construction in linguistically and culturally diverse graduate classrooms. Language and Intercultural Communication, 18(2), 184-203. https://doi.org/10.1080/14708477.2017.1337778

Lin, Y., \& Kingminghae, W. (2014). Social support and loneliness of Chinese international students in Thailand. Journal of Population and Social Studies, 22(2), 141-157. doi:10.14456/jpss.2014.10

Merriam, S. B. (2009). Qualitative research: A guide to design and implementation. San Francisco: Jossey-Bass.

Ministry of Education. (2015). Statistical summaries. Retrieved September 10, 2015, from http://english.moe.gov.tw/lp.asp?ctNode=11429\&CtUnit=1345\&BaseDSD=16\&mp=1

Morita, N. (2004). Negotiating participation and identity in second language academic communities. TESOL Quarterly, 38(4), 573-603. https://doi.org/10.2307/3588281

Myles, J., \& Cheng, L. (2003). The social and cultural life of non-native speaking graduate students at a Canadian university. Journal of English for Academic Purposes, 2(3), 247-263. https://doi.org/10.1016/S1475-1585(03)00028-6

Nambiar, R., \& Noraini, I. (2013). Exploring the academic literacy socialization of Mainland China undergraduates in a Malaysian tertiary institution. International Education Studies, 6(6), 35-44.

Park, E., Klieve, H., Tsurutani, C., \& Harte, W. (2017). International students accented EnglishCommunication difficulties and developed strategies. Cogent Education, 4(1), 1314651-1$1314651-15$.

Seloni, L. (2012). Academic literacy socialization of first year doctoral students in the US: A microethnographic perspective. English for Specific Purposes, 31(1), 47-59. https://doi.org/10.1016/j.esp.2011.05.004

Vygotsky, L. (1978). Mind in society: The development of higher psychological processes. Cambridge, MA: Harvard University Press.

Zappa-Hollman, S., \& Duff, P. A. (2015). Academic English socialization through individual networks of practice. TESOL Quarterly, 49(2), 333-368. https://doi.org/10.1002/tesq.188

SHU-WEN LAN, Ph.D., is an Assistant Professor in the Department of Modern Languages at National Pingtung University of Science and Technology in Taiwan. Her research interests mainly include EFL teaching and learning, the educational experiences of international students, and cross-cultural interaction. Email: swlan@mail.npust.edu.tw 